\title{
A Compact High Current Vacuum Diode Based on a Ceramic-Metal Welding Interface
}

\author{
T. Xun*, J.D. Zhang, H.W. Yang, Y. Wang and Z.X. LiU \\ College of Opto-Electric Science and Engineering \\ National University of Defense Technology, Changsha, Hunan, 410073, China
}

\begin{abstract}
For one kind of high current diodes composed of a ceramic-metal welding vacuum interface, the electrical design was presented. For compactness, a radial type insulator and a cone-column anode crust were adopted. The shielding methods around cathode and anode region were applied to mitigate the influence of welding solder to vacuum flashover. Finite Element Analysis (FEA) simulation results indicated that by adjusting the anode outline and shielding shape, the electric fields along the ceramic were well distributed. High voltage test was conducted on a long-pulse accelerator and experimental results confirm the theoretic design: the diode can stably hold on $400 \mathrm{kV}$ and $200 \mathrm{~ns}$ voltage pulse.
\end{abstract}

PACS numbers: 52.59.Mv, 73.20.-r, 84.70.+p

\section{Introduction}

Vacuum diodes are among the most important parts of high current accelerators [1]. For practical use, there is a trend to increase the hold-off voltage and maintain high vacuum sealed state for a long time [2]. Recently, in order to improve the vacuum condition, hybrid hard-tube technologies are introduced to traditional diodes by eliminating all plastic components and replacing o-ring seals with ceramic-metal welding [3]. However, because of vacuum flashover [4], the ceramic interface between liquid in pulse forming line (PFL) and vacuum always becomes the chock point of high power flow and it needs more consideration to the enhanced electric field around the triple junction (TJ) where ceramic, metal and vacuum are contiguous [5]. In this paper, with a ceramic disk diameter no more than $230 \mathrm{~mm}$, the radial insulation structure based on ceramic-metal welding is described and tested.

\section{Diode design}

For a compact diode, according to the design rules of radial insulators in vacuum $[6,7]$, a novel "cone-column" outline of anode crust was applied to enlarge the chamber cavity. The taper part insured the angle between electric field line and ceramic surface. At cathode and anode TJ, without additional grading rings, convexity and filter angle were used to shield electric field around the welding solder. The field along ceramic surface can be modulated by adjusting the detailed frame of anode outline

\footnotetext{
* corresponding author; e-mail: xtao_0301@hotmail.com
}

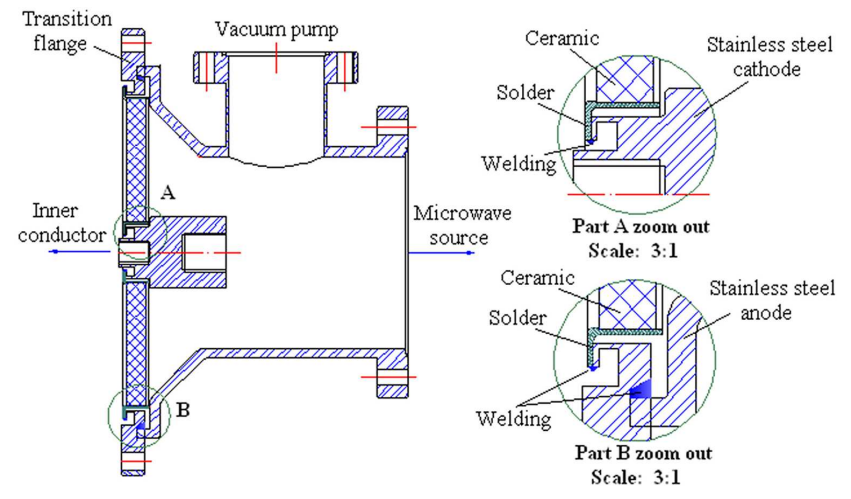

Fig. 1. Layout of the high current diode based on ceramic-metal welding.

and regulating the shields. The diagram of the configuration is illustrated in Fig. 1. The outer diameter of the ceramic is $223 \mathrm{~mm}$, with the thickness of $10 \mathrm{~mm}$. The angle between taper part of the anode crust and ceramic surface is about 37 degrees. The diode was connected to PFL through the flange and the high voltage pulse was applied via the inner conductor.

\section{Electrical field consideration}

A two-dimensionally axial-symmetric model was set up to calculate the electric field distribution by employing ANSYS software. In the simulations, the cathode voltage is set minus $400 \mathrm{kV}$ and the anode is set zero. The relative permittivity of ceramic, vacuum and dielectric water was set to 8.8, 1.0, and 80, respectively. The obtained results are shown in Fig. 2. In Fig. 2a, the value of per 


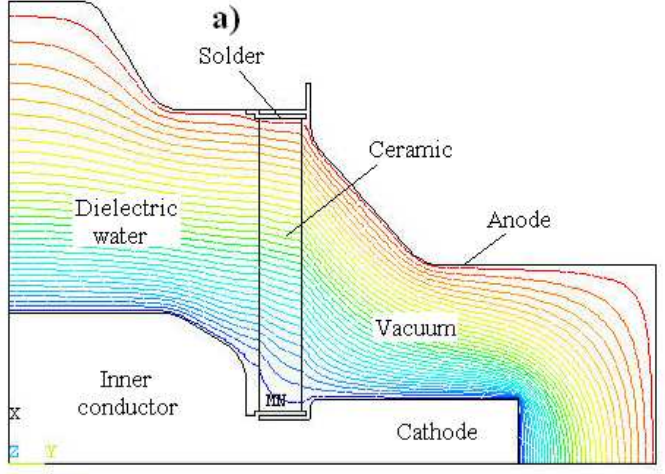

b)

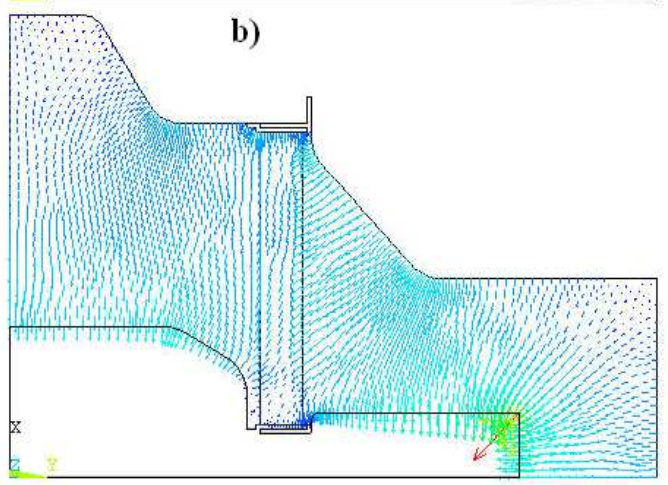

Fig. 2. (a) Equipotential line distribution. (b) Electric field vector distribution.

unit equipotential line is $13 \mathrm{kV}$; and Fig. 2b suggests that the field round the triple junction is small.

The radial component of electric field $\left(E_{\mathrm{r}}\right)$ and the angle of electrical field line variation $(\theta)$ along ceramic surface are also calculated and shown in Fig. 3.

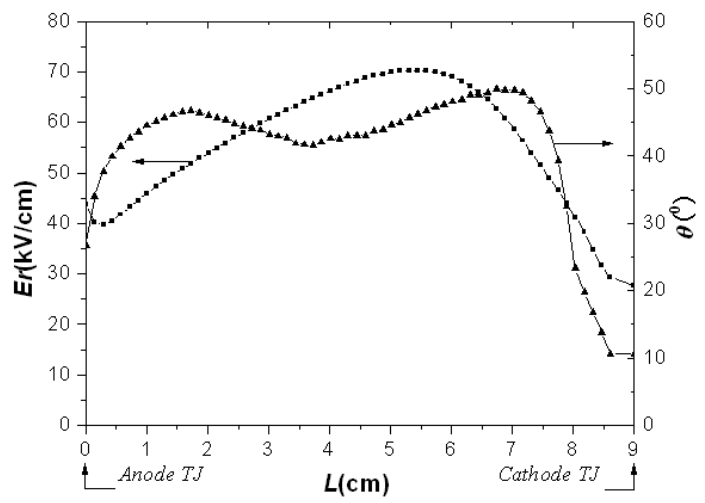

Fig. 3. Electrical field $E_{r}$ and $\theta$ variation along ceramic surface.

Through the electrostatic simulations, the main effects of the design can be summarized: (1) In $400 \mathrm{kV}$ voltage level, the average value is $56 \mathrm{kV} / \mathrm{cm}$ and the maximum value is $70 \mathrm{kV} / \mathrm{cm}$. (2) The electric field around the cathode TJ region has been well controlled $(<30 \mathrm{kV} / \mathrm{cm})$. (3) The angle between electric field line and insulator surface is mostly maintained near 45 degree.

For a $200 \mathrm{~ns}$ pulse width and a $320 \mathrm{~cm}^{2}$ ceramic surface area, the breakdown value of $120 \mathrm{kV} / \mathrm{cm}$ is obtained by J.C. Martin's empirical formula [8]. Considering a safe factor of 1.5, the actual operating field along ceramic surface should be no more than $80 \mathrm{kV} / \mathrm{cm}$. According to the simulated results of $E_{\max }<70 \mathrm{kV} / \mathrm{cm}$, the interface is able to hold on at least $400 \mathrm{kV}$ of applied voltage pulse. In this level, the field near the CTJ is $27 \mathrm{kV} / \mathrm{cm}$, which satisfies Shipman and Spence's design criteria [9].

\section{Experimental results}

The high voltage test for the diode was carried out on a long-pulse accelerator [10]. It mainly consists of an energy-storage capacitor, a pulsed transformer, a dielectric water-PFL, a gas switch and a transition section also filled with dielectric water. The diode was assembled behind the transition part. The maximum withstand voltage of the PFL is $800 \mathrm{kV}$ with $200 \mathrm{~ns}$ pulse duration.
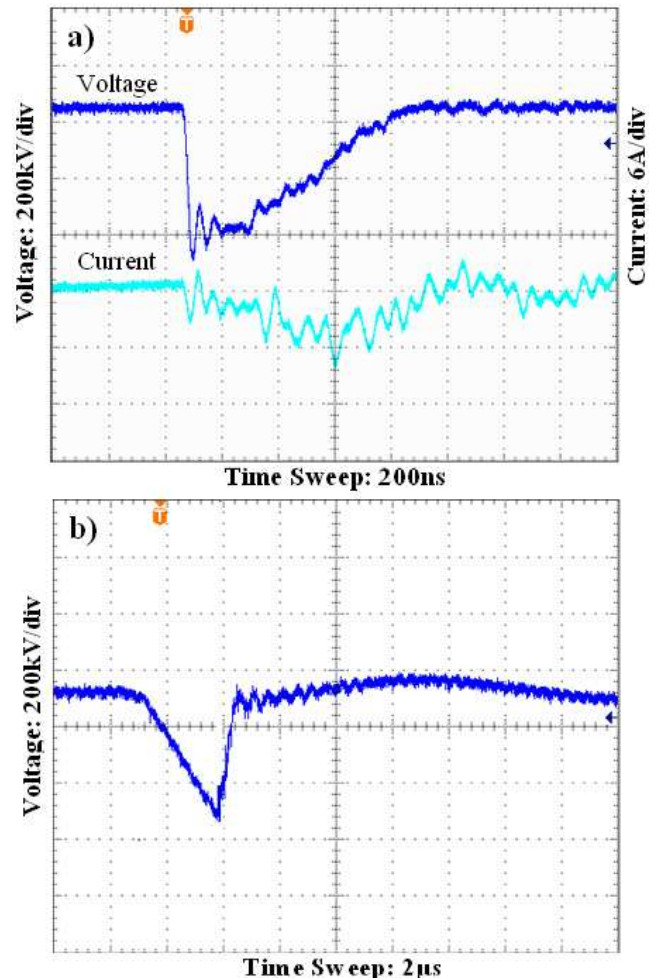

Fig. 4. (a) Voltage and current waveform on the vacuum diode. (b) Charging voltage waveform on PFL.

In the experiment, the vacuum condition was about $3 \times 10^{-3} \mathrm{~Pa}$, and the resistivity of dielectric water was kept at $13.26 \mathrm{M} \Omega \mathrm{cm}$. The diode voltage and current were measured by resistive divider and the mural galvanometric loop both located on transition part. The operating process for insulating test is as follows: increases the charging voltage gradually until the flashover occurs for three times continually, then step down the voltage until 
it does not occur any more. The first voltage that the diode can hold on at least three times with no flashover can be considered reliable [11]. Typical waveforms of the diode voltage and current are shown in Fig. 4a, correspondingly, the charging waveform of the PFL is shown in Fig. 4b.

In our test, the cathode material, made of brass, has a weak ability to emit electrons, and the distance of A-K gap is long, so that the diode can be regarded as a turn-off load and the current is small. So, the peak voltage of diode $(436 \mathrm{kV})$ is approximate to the value of charging voltage on PFL $(495 \mathrm{kV})$, and the actual pulse width is more than 200 ns due to the repetitious wave reflection between load and PFL.

No less than 70 shots were taken primarily, and the diode can work stably on the pulse condition of $400 \mathrm{kV}$ and $200 \mathrm{~ns}$. When the voltage on PFL exceeded $500 \mathrm{kV}$, the probability of flashover on the diode rose.

\section{Conclusions}

The design of a compact, ceramic--metal welding vacuum diode for high current accelerators has been detailed. A practical approach for the inhibition of surface flashover along ceramic has been proposed and successfully demonstrated under $400 \mathrm{kV}$ and $200 \mathrm{~ns}$ pulse voltage condition. The efforts for configurating a small size ceramic-metal welding insulation structure are also required to push design limits for future larger high voltage vacuum diodes.

\section{Acknowledgments}

The work was supported by National High-Tech Research and Development Programme of China.

\section{References}

[1] S.D. Korovin, I.K. Kurkan, S.V. Loginov, I.V. Pegel, S.D. Polevin, S.N. Volkov, Laser Part. Beams 21, 175 (2003).

[2] R.B. Miller, IEEE Trans. Plasma Sci. 26, 340 (1998).

[3] J. Benford, G. Benford, IEEE Trans. Plasma Sci. 25, 311 (1997).

[4] H.C. Miller, IEEE Trans. Electrical Insulation 28, 512 (1993).

[5] P.A. Arnold, IEEE Trans. Electrical Insulation 23, 17 (1993).

[6] High Voltage Vacuum Insulation, Ed. R.V. Latham, Academic Press, London 1995, Ch. 9.

[7] J.M. Wetzer, IEEE Trans. Dielectrics Electrical Insulation 4, 349 (1997).

[8] J.C. Martin on Pulsed Power, T.H. Martin, A.H. Gueuther, M. Kristiansen, Plenum Press, New York 1996, Ch. 2.

[9] High Power Switches, Ed. I. Vitkovitsky, Van Nostrand Reinhold Company Inc., New York 1987, Ch. 4.

[10] J.L. Liu, T.W. Zhan, J. Zhang, Z.X. Liu, J.H. Feng, T. Shu, J.D. Zhang, X.X. Wang, Laser Part. Beams 25, 593 (2007).

[11] Y. Osamu, H. Takehisa, N. Toshihiro, H. Muneaki, IEEE Trans. Electrical Insulation 24, 991 (1989). 